Presented at the ASME International Mechanical Engineering Congress and Exposition, November 15-19, 1999, Nashville, Tennessee.

Published in Crashworthiness, Occupant Protection and Biomechanics in Transportation

Systems, ASME, AMD Vol. 237/BED Vol. 45, 1999.

\title{
A Numerical Evaluation of Protection Strategies for Cab Car Crashworthiness
}

\author{
Richard Stringfellow \\ Ronald Mayville \\ Robert Rancatore
}

Arthur D. Little, Inc.

Cambridge, Massachusetts 02140

\begin{abstract}
The operator and passengers in cab cars are particularly vulnerable to collisions with objects or with other trains because of their proximity to the point of collision. We present one part of a larger study in which we examined several strategies for improving the protection afforded to the operator and the passengers in cab car collisions. These strategies include: strengthening key cab-end structural elements, such as corner posts, collision posts and end beams; locating the operator between the collision posts rather than to one side of the control cab; and implementing crush zones into the ends of the cab as part of a crash energy management design for the entire train. Here we focus on the first of these strategies, evaluating the effectiveness of strengthened cab-end structures through explicit dynamic finite element-based calculations simulating the crush behavior of the cab car. There calculations were made for conditions representative of a number of collision scenarios based upon recent accidents, including several oblique collisions. The results of these calculations suggest that such strengthening can significantly increase the tolerable collision speeds that can be withstood without compromising the operator and passenger volumes.
\end{abstract}

\section{INTRODUCTION}

The crashworthiness of rail vehicles has been the focus of a substantial amount of research over the past few years. This increase in research interest can be attributed to several factors. In 1995, the planned introduction of high-speed trains prompted an examination of available technologies for providing greater protection in the event of a collision. In addition, advances in computer modeling capabilities have made it possible to evaluate, without extensive testing, the consequences of collisions and the effect that design improvements have in increasing the safety of rail vehicle operators and passengers.

This study examined certain aspects of the crashworthiness of cab cars. Cab cars carry passengers and in the U.S. look similar to passenger coach cars, but include an operator's control stand at one or both ends. Such cars are used to control two types of trains: multiple unit (MU) trains, in which each of the cars is powered, and push-pull trains, in which a locomotive pushes the train in one direction. When an operator controls the train from the front of a cab car of the type currently used in U.S. operations, he or she is within inches of the very end of the vehicle.

Thus, protecting the operator of a cab car during a collision is a particularly daunting challenge, because the operator cab has little structure separating it from a colliding vehicle or object. The extent of allowable crush of the vehicle end before the operator volume is compromised is very small - on the order of one foot. Moreover, for conventional train designs, nearly all of the energy in a front-end collision is absorbed by the forward end of the lead vehicle. Figure 1 shows the amount of kinetic energy, 
in ft-lbf, that resides in a train consisting of a locomotive, six passenger cars, and a cab car (a total mass of $800,000 \mathrm{lbm}$ ), as a function of the speed at which such a train is traveling. In a collision, very little of this energy can be absorbed by crushing of the lead vehicle's end structure before this one foot safe limit is exceeded.

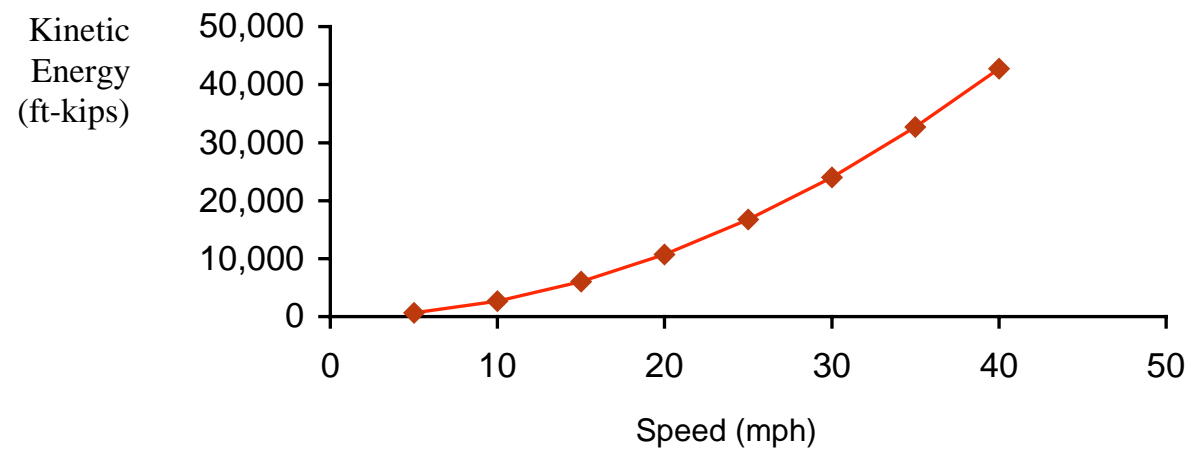

Figure 1. Kinetic energy of a train consisting of a locomotive, six passenger cars, and a cab car, as a function of the speed at which it traveling.

The situation is particularly severe when the colliding object is offset from the centerline of the vehicle and strikes only the corner of the cab car, because the corner is much weaker than the center of the cab-end, where the collision posts are located. Such offset collisions occur when trains collide in a switch or when a cab car strikes a highway vehicle that has just entered a grade crossing.

Recent accidents involving cab cars provide grim evidence that the ends of these types of vehicles can be severely damaged in collisions with other vehicles or with objects. In order to improve the safety of these vehicles, the Federal Railroad Administration (FRA) is planning to adopt new specifications for the design of cab car end structures.

Previous research by the Volpe Center and Arthur D. Little [1,2] has indicated that cab cars can tolerate only low-speed offset collisions with other trains before the amount of vehicle crush exceeds safe values. In particular, a centered collision between a cab car-led train and another comparable commuter train above a closing speed of $12 \mathrm{mph}$ was found to eliminate the survivable space for the operator in the cab car. These studies have also provided evidence that the crashworthiness of cab cars in offset collisions could be substantially improved by requiring greater corner strength and energy absorption capability and that these greater requirements can be achieved through relatively modest structural changes requiring little added weight and cost.

Under a research program sponsored by the Volpe Center of the Department of Transportation, we have conducted a study which examines the protection provided by vehicles designed and built to current industry practice and the efficacy of different strategies for improving the protection afforded to the operator and to the passengers in collisions involving cab cars. In this study, several protection strategies were explored, including:

- $\quad$ strengthening of key cab end structural elements, such as corner posts, collision posts and end beams;

- locating the operator between the collision posts rather than in the corner;

- implementing crush zones into the ends of the cab.

Each of these strategies was examined with respect to a number of collision scenarios based upon recent accidents. Both centered and offset collisions were considered. 
In this paper, we review the results of research performed in order to examine the effectiveness of the first of the three noted strategies: strengthening of key cab-end structural elements. Cab-end structural modifications were evaluated through a series of collision simulations representative of accidents that have occurred. We first present a review of several representative accidents that were examined in order to determine a set of collision scenarios with which to judge the effectiveness of structural modifications. We then review the approach that we used to perform these evaluations and the results of our calculations.

\section{Review of Accidents}

The selection of collision scenarios for evaluating cab-end improvements was based upon a review of several recent cab car accidents. The conditions and consequences of these accidents are briefly summarized below.

\section{Secaucus, New Jersey accident (an offset collision)}

In February of 1996, a collision occurred between the cab car of a commuter train (consisting of a cab car, four coach cars and a locomotive) and the locomotive of another commuter train (with a cab car, four coach cars and a locomotive) [3]. There were three fatalities: the locomotive operator, the cab car operator, and a passenger in the colliding cab car. In addition, there were 12 injuries, all in the leading cab car. The collision occurred while one of the lead cars was traversing a switch, resulting in a lateral misalignment and an angle-of-incidence between the cars. The cab car, traveling at $18 \mathrm{mph}$, struck the front right corner of the locomotive, which was traveling at $53 \mathrm{mph}$ in the opposite direction, with an angle of impact of about 7 degrees. Both cab car collision posts remained intact, with only the right collision post sustaining damage. The right corner post was torn away, and the cab car raked down the side of the locomotive, which subsequently derailed. The cab car, which also derailed, continued to rake down the side of the locomotive-led consist.

\section{Silver Spring, Maryland accident (an offset collision)}

In this same month, a similar collision between the cab car of a cab car-led train and the locomotive of another train occurred at a closing speed of $65 \mathrm{mph}$ [4]. Here again, the accident occurred while one of the lead cars was traversing a switch. There were 11 fatalities, most of which were caused by the ensuing fire. However, it appears that some of the fatalities were caused by crush from the collision.

\section{Portage, Indiana accident (an offset collision)}

In June of 1998, a train made-up of two cab cars traveling at a speed of $57 \mathrm{mph}$ collided at a gradecrossing with a flat bed truck carrying a large coil of sheet steel. The 6-foot diameter by 4-foot wide coil of sheet steel was oriented on the bed of the truck such that the collision occurred in the manner depicted schematically in Figure 2. It appears that the coil struck the cab end above the floor and offset to one side of the vehicle (Figure 3). The coil appears to have penetrated about three to four feet into the left side of the cab. The left collision post fractured just above a shear reinforcement plate. There were three fatalities from the crush and intrusion of the coil into the cab car.

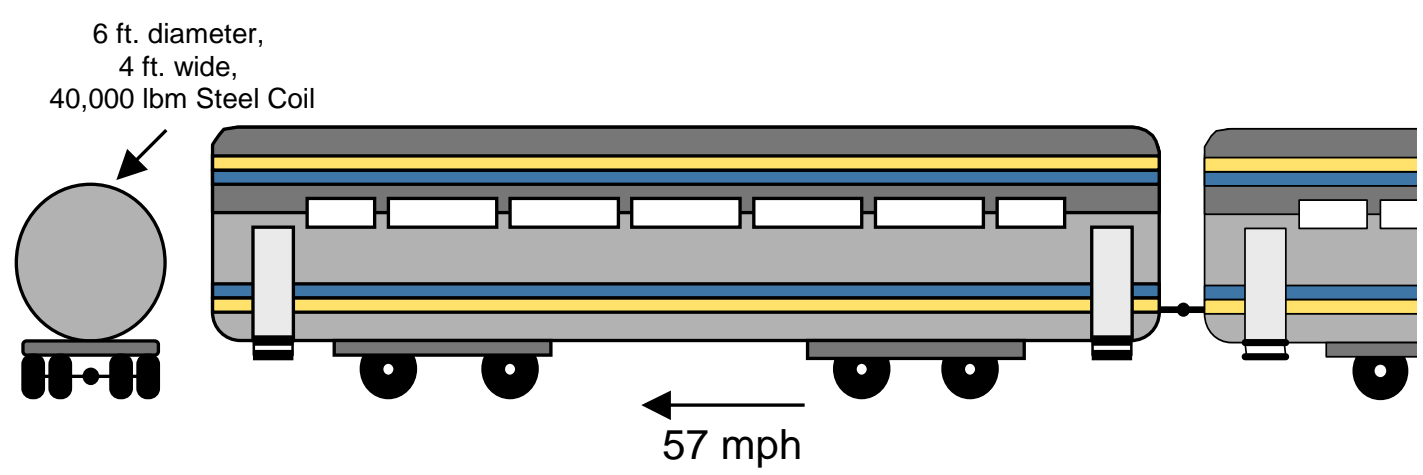

Figure 2. Schematic of June, 1998 collision between a cab car and a flat-bed truck carrying coils of sheet steel. 


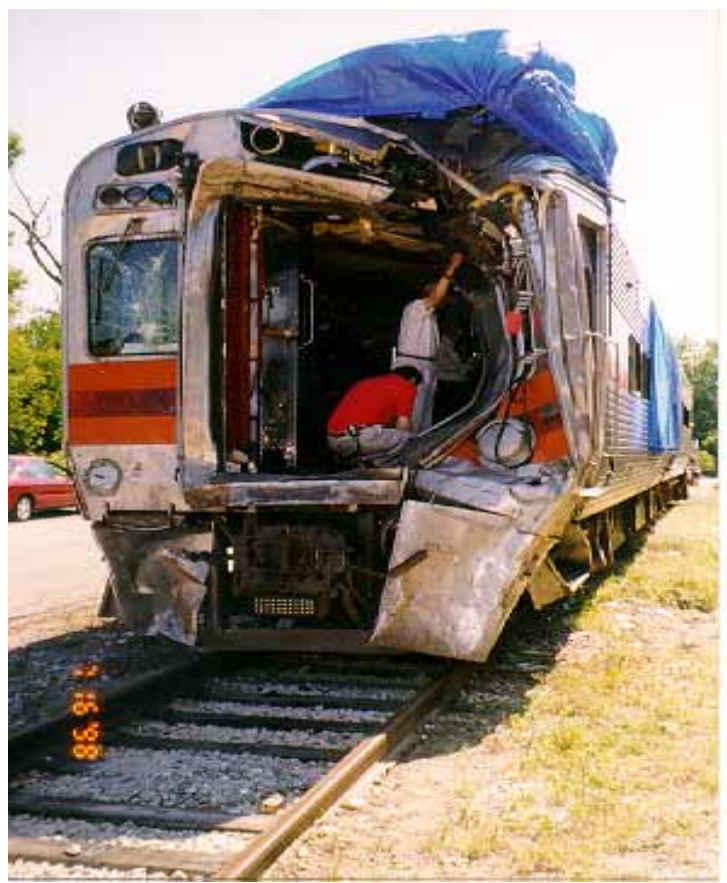

Figure 3. The front end of the cab car following the collision.

Beverly, Massachusetts accident (a centered collision)

In August of 1981, the cab car of a commuter train collided with the lead locomotive of another commuter train, causing several serious injuries [5]. This accident occurred at closing speed of about $31 \mathrm{mph}$, resulting in severe deformation of the cab car underframe, followed by override of the cab car onto the locomotive.

\section{Gary, Indiana accident (an offset collision)}

In January of 1993, two multiple-unit passenger trains collided on parallel but laterally offset tracks that shared a bridge [6]. One of the trains was at rest and the other was traveling at a speed of $32 \mathrm{mph}$. Impact occurred between opposite corners of the two lead cab cars, resulting in destruction of the colliding corner posts, and raking of the two vehicle sides along one another for a distance of about 25 feet. There were seven passenger fatalities.

These five accidents provide examples of the types of collisions against which one would like to provide greater protection. Four of the five accidents involved offset collisions in which only the corners of the vehicle were directly challenged. One of these four further involved a collision that occurred a substantial distance above the underframe.

Based upon consideration of the nature of these accidents, we selected three collision scenarios for use in evaluating the protection provided by vehicles built to current standards and those including the various protection strategies that were part of this research. Two of these scenarios were used to evaluate the effectiveness of strengthened cab-end structures. These are:

- Scenario 1: An offset collision between two commuter trains, in which the cab car impacts a locomotive;

- Scenario 2: A collision between a heavy object, in the form of a steel coil, and a cab car, with the coil impact direction offset from the centerline of the cab car.

The collision speed in each of these scenarios at which the tolerable amount of crush was exceeded was used as a measure of crashworthiness. 


\section{APPROACH}

Our approach to evaluating the effectiveness of strengthening cab car end structures focused on evaluating the extent of crush in simulated collision scenarios representative of recent accidents. In making such evaluations, there are two distinct considerations: protection of the cab operator and protection of the passengers. Although an optimum strategy is one that protects both the operator and passenger volumes, it is also necessary to assess improvements with respect to each type of occupant separately. For purposes of our evaluation, we defined a "loss of operator volume" to occur when the collision has produced one foot of crush in the operator's cab, and a "loss of passenger volume" to occur after three feet of crush in the passenger compartment. Quantitative assessments of safety improvements were therefore made in terms of these crush distances.

The determination of cab car crush was made using finite element methods. The ABAQUS/Explicit code was used to carry out the calculations. The calculations were made using a model based on an AmFleet Intercity coach car manufactured by Bombardier. This vehicle weighs about 104,000 lbm, including $24,000 \mathrm{lbm}$ of structural material. A finite element model originally developed in [7] was significantly modified so that it had baseline structural properties that are typical of existing cab cars. Only the end of the car was modeled in detail (to a distance of about six feet past the body bolster). The remainder of the car was modeled using lumped mass and spring elements. A total of approximately 24,000 elements (mostly plate type elements, a few solid elements) were used to discretize the cab end structure. The colliding object, representing the end of another vehicle or an object, was modeled as a rigid body. The collisions were simulated by defining an initial velocity for the rigid body and letting the model calculate the forces that arise as the cab end structure is crushed by the rigid body, dissipating the initial kinetic energy of the colliding body through plastic deformation. The representative mesh used in the calculations is shown in Figure 4, together with a rigid body representation of the colliding locomotive underframe used in one of the sets of calculations described below.) A detail of the mesh showing key cab-end structural components is shown in Figure 5.

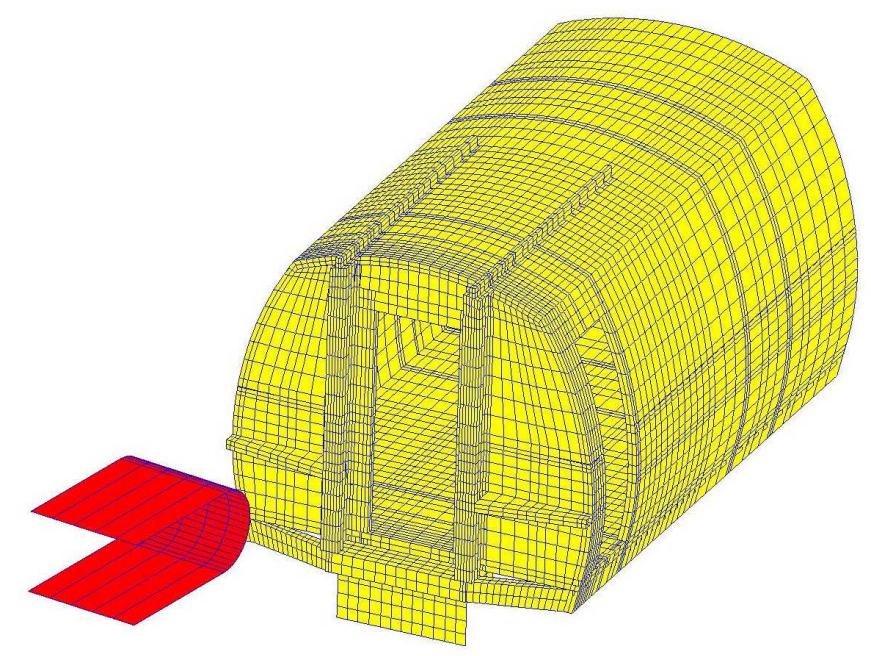

Figure 4. The finite element mesh used for the cab car crush calculations, shown with a rigid surface representing a colliding locomotive underframe. 


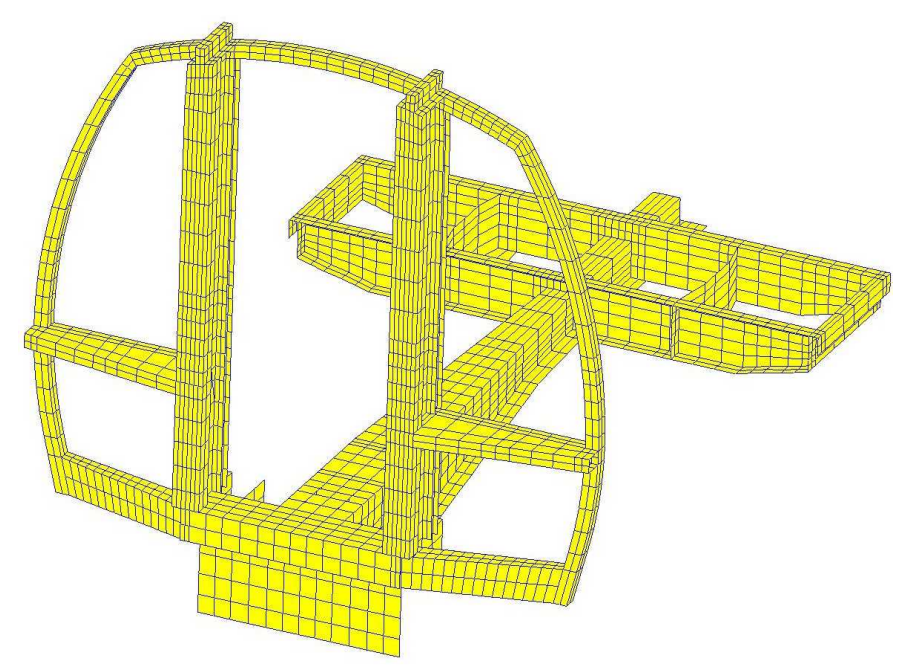

Figure 5. Detail of cab car mesh showing key cab-end structural components.

Current industry practice is to design cab cars to the specifications shown in Table 1.

Table 1: Strength requirements used in current industry practice for cab cars.

\begin{tabular}{|l|l|l|}
\hline $\begin{array}{l}\text { Structural } \\
\text { element }\end{array}$ & $\begin{array}{l}\text { Required strength at } \\
\text { floor level }\end{array}$ & $\begin{array}{l}\text { Required strength at 18 inches } \\
\text { above the floor }\end{array}$ \\
\hline Corner post & $\begin{array}{l}150,000 \mathrm{lbf} \\
\text { (ultimate) }\end{array}$ & $30,000 \mathrm{lbf}$ (yield) \\
\hline Collision post & $\begin{array}{l}300,000 \mathrm{lbf} \\
\text { (ultimate) }\end{array}$ & $300,000 \mathrm{lbf}$ (ultimate) \\
\hline
\end{tabular}

New car specifications often include an additional requirement that failure at the ultimate load should occur in the structural element and not at the connections. Otherwise, there are rarely explicit specifications used to ensure that substantial energy absorption is achieved. That is, a design in which fracture and complete loss of load occurs immediately after the attainment of ultimate load meets the specifications, despite the fact that such a design would have poor energy absorbing capacity.

Increases in the strength specifications for corner and collision post structural elements in cab cars are currently under active consideration by the FRA and the rail industry as the favored approach to improving cab car crashworthiness. These elements also include the end beam and the side sill, as well as other structural members which carry load from the corner posts to the collision post, including top plates and mid-height lateral supports. The basis of this concept is that vehicles with higher strength at the ends and corners will be able to resist crush and penetration of a wider set of objects, and that higher collision energies, and hence speeds, will be tolerable without loss of operator and passenger volumes.

One must carefully evaluate whether such changes fundamentally change the crush behavior of the cab end structure. For example, increasing the strength of the collision posts likely renders them stiffer as well, increasing the dynamic loads produced in a high-speed collision. It is also possible that a strengthened structure is more susceptible to failure by fracture, as opposed to bending collapse, thereby eliminating the increased energy absorption capacity brought about by the strength increase. Another consequence of increasing the strength of the collision posts may be that the draft sill fails prior to the collision posts failing due to the increased bending moment that it experiences.

We evaluated several cab end structural modifications, including:

- Extending the side sill to the front corner of the cab so that a higher corner load can be resisted (a modification that requires eliminating the stairwell);

- Increasing the strength of the end beam and corner posts so that a higher corner load can be resisted without sacrificing the stairwell; 
- Increasing the strength of lateral supports that connect the corner posts to the collision posts, including a "top plate" that connects the top of the corner post to the top of the collision post, and a mid-height lateral support" that connects the corner post to the collision posts about two feet above the floor;

- Increasing the strength of the collision posts.

Three collision scenarios (scenario 1 and two variations of scenario 2) were used to evaluate the effectiveness of cab end structural modifications. The structural elements that were evaluated using these scenarios and the modifications that were made to each element are summarized in Table 2.

Increases in strength were achieved by increasing the section properties of structural elements. For scenario 1, the side sill was not strengthened, just extended to join the base of the corner post on the operator's side of the cab car. Such a strategy eliminates the possibility of a stairwell at this location, but nonetheless has been favorably greeted by industry. Increasing the strengths of the collision posts necessitated reinforcing the buffer sill to which it is attached at its base.

A few issues that must be considered when strengthening each of these components include the additional weight of the added structure, including the weight of any supporting structures and the additional cost, including material and manufacturing costs, of the added structure.

Table 2: Collision Scenarios and associated cab car end structural element strength modifications evaluated.

\begin{tabular}{|l|l|l|l|}
\hline $\begin{array}{l}\text { Collision scenario } \\
\text { used for evaluation }\end{array}$ & $\begin{array}{l}\text { Structural elements } \\
\text { modified }\end{array}$ & $\begin{array}{l}\text { Baseline strength } \\
\text { requirement }\end{array}$ & Modified strength \\
\hline $\begin{array}{l}\text { Scenario 1: offset } \\
\text { collision with a loco }\end{array}$ & $\begin{array}{l}\text { (a) Extended side } \\
\text { sill }\end{array}$ & $\begin{array}{l}150,000 \mathrm{lbf} \\
\text { ultimate at base }\end{array}$ & $350,000 \mathrm{lbf}$ \\
\cline { 2 - 4 } & $\begin{array}{l}\text { (b) End beam plus } \\
\text { mod. (a) }\end{array}$ & $\begin{array}{l}150,000 \mathrm{lbf} \\
\text { ultimate at base }\end{array}$ & $500,000 \mathrm{lbf}$ \\
\hline $\begin{array}{l}\text { Scenario 2 } \\
\left(1^{\text {st }} \text { variation): corner }\right. \\
\text { post-centered collision } \\
\text { with a steel coil }\end{array}$ & $\begin{array}{l}\text { (a) End beam and } \\
\text { corner post }\end{array}$ & $\begin{array}{l}150,000 \mathrm{lbf} \\
\text { ultimate at base, } \\
30,000 \mathrm{lbf} \text { yield at } \\
18 \text { inches }\end{array}$ & $\begin{array}{l}300,000 \mathrm{lbf} \text { at base, } \\
100,000 \text { lbf yield at } \\
18 \text { inches }\end{array}$ \\
\cline { 2 - 4 } & $\begin{array}{l}\text { (b) top plate plus } \\
\text { mod (a) }\end{array}$ & none & $\begin{array}{l}150,000 \text { lbf ultimate } \\
\text { at end }\end{array}$ \\
\cline { 2 - 4 } & $\begin{array}{l}\text { (c) mid-height } \\
\text { lateral support plus } \\
\text { mod (b) }\end{array}$ & none & $\begin{array}{l}150,000 \mathrm{lbf} \text { ultimate } \\
\text { at end }\end{array}$ \\
\hline $\begin{array}{l}\text { Scenario 2 } \\
\left(2^{\text {nd }} \text { variation): }\right. \\
\text { collision post- } \\
\text { centered collision with } \\
\text { a steel coil }\end{array}$ & Collision posts & $\begin{array}{l}300,000 \mathrm{lbf} \\
\text { ultimate up to } 18\end{array}$ & $\begin{array}{l}300,000 \mathrm{lbfultimate} \\
\text { up to } 30 \text { inches }\end{array}$ \\
\hline
\end{tabular}

\section{RESULTS}

Effectiveness of Increased Corner Support

The first set of simulations examined the effectiveness of increased support for the corner of the cab end. The scenario used to evaluate this design change is representative of an off-center collision wherein the underframe of a locomotive strikes the corner of a cab car and rakes down the side of the vehicle (much like the Secaucus, NJ accident).

The properties of the primary structural components at the end of the car were modified, as necessary, to produce a model that could serve as a baseline structure having properties consistent with existing cab cars and meeting the baseline strength requirements shown in Table 1 . 
The locomotive underframe was idealized as a rigid body, with a mass of $672.9 \mathrm{lb}-\mathrm{sec}^{2} /$ in (a weight of $260,000 \mathrm{lbm}$ ), positioned so that it strikes the corner post at floor level, overlapping the front of the vehicle by about six inches. The front end of the rigid body was modeled as a 20 -inch diameter cylindrical surface in order to provide smooth contact, and was oriented $10^{\circ}$ off the lateral axis of the vehicle to represent the angled geometry of the deformed locomotive corner in the Secaucus, NJ accident (see Figure 4). An initial speed of $30 \mathrm{mph}$ was prescribed to the rigid body.

In the baseline model, the side sill stops at the door frame, about 45 inches behind the front of the corner post, to accommodate a stairwell. Therefore, crush of the cab end is resisted primarily through bending of the end beam away from the center sill. Two modifications to the baseline corner structure were considered. In the first, the side sill, with a longitudinal strength of about 200,000 lbf, was carried forward and tied-in to the corner post at the connection to the end beam. In the second, in addition to carrying the side sill forward, the strength of the end beam was doubled so that it resists an end load of 300,000 lbf.

The load-displacement responses of the baseline and modified structures are shown in Figure 6. For the baseline case, the load quickly builds up to $300,000 \mathrm{lbf}$ and then drops to an average level of about 200,000 lbf over the next 20 or so inches before dropping to a very small value. The load then builds up again to a second peak of about $375,000 \mathrm{lbf}$ at a crush distance of about 36 inches. This second peak corresponds to the collision of the rigid surface with the frame element at the back of the door, where the side sill begins.

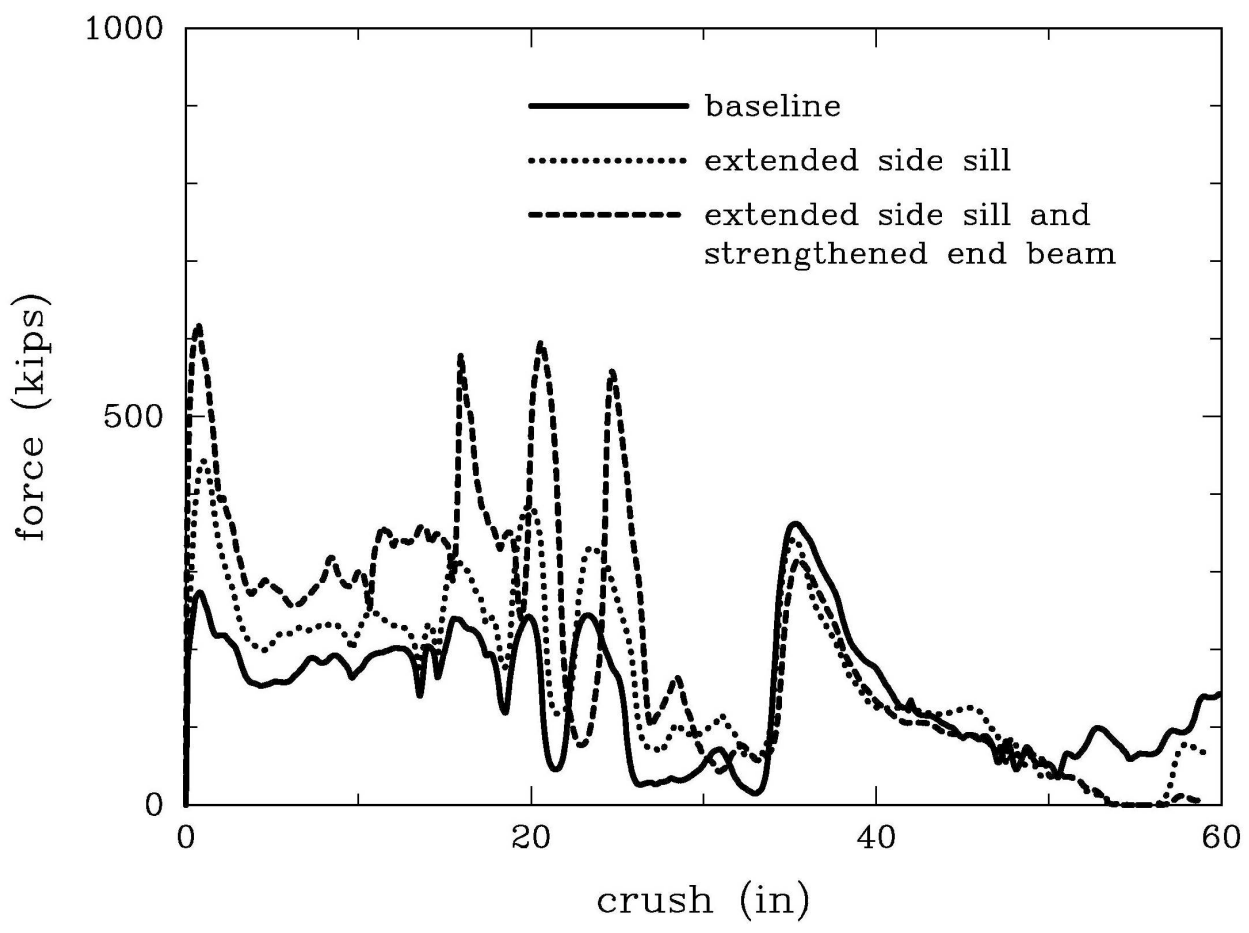

Figure 6. Comparison of load-displacement response to collision with a locomotive underframe for two modified cab end corner structures (a side sill that has been carried forward and a strengthened end beam) to that of the baseline cab end.

With regard to Figure 6, we note that the force-crush data has been filtered to remove high frequency oscillations in the force. We note that there is a relatively low frequency oscillation in the force for crush levels between about 17 and 27 inches. This appears to be a dynamic effect that arises because the end 
beam becomes deformed to a point where it loses contact with the colliding rigid surface, snaps back elastically, and then vibrates. We do not believe that these oscillations affect the outcome of our comparisons. Finally, we note that self-contact of the side sill was not modeled. It is therefore likely that the model under-predicts the resistance provided by the side sill, particularly for crush of the side sill beyond the doorway, where it is better supported, and may fold up on itself rather than buckle. Since the aim of our study was to compare the resistance of baseline and modified corner structures for crush levels ranging from 12 to 36 inches, we did not attempt to improve this aspect of the model.

For the case in which the side sill has been carried forward but the end beam has not been strengthened, the increase in the initial peak in load is sizable, about 60 percent. However, because the side sill in this vehicle has not been designed to provide crush resistance, it quickly buckles, and provides an increase in resistance of only about 40 percent overall. Strengthening the end beam in addition appears to provide much more substantial increase in resistance, nearly doubling crush resistance.

Table 3 summarizes the results of these calculations from the point of view of energy absorption or, equivalently, tolerable collision speed. This table shows the speed at which the kinetic energy of (a) a $260,000 \mathrm{lbm}$ locomotive or (b) a 40,000 lbm truck can be completely absorbed without loss of the operator or occupant volumes (which we defined previously to be one foot and three feet, respectively). The increases in tolerable speed, which are proportional to the square roots of the increases in absorbed energy, are $17 \%$ for 12 inches of crush and $19 \%$ for 36 inches of crush for the extended side sill only, and 33\% for 12 inches of crush and 39\% for 36 inches of crush for the extended side sill and strengthened end beam. This translates into an increase in tolerable speed of only a few mph for collision with a locomotive, but up to about $7 \frac{1}{2} \mathrm{mph}$ for collision with a truck.

Table 3. The effect of extending the side sill on speeds at which the operator and passenger volumes become compromised in collisions with (a) a $260,000 \mathrm{lbm}$ locomotive and (b) a 40,000 lbm truck.

\begin{tabular}{|l|c|l|c|c|}
\hline \multirow{2}{*}{ Case } & \multicolumn{2}{|l|}{$\begin{array}{l}\text { Maximum safe closing speed } \\
\text { for the operator, in mph (based } \\
\text { upon 1 ft of crush) }\end{array}$} & \multicolumn{2}{|l|}{$\begin{array}{l}\text { Maximum safe closing speed for } \\
\text { the passengers, in mph (based } \\
\text { upon 3 ft of crush) }\end{array}$} \\
\cline { 2 - 5 } & $\begin{array}{l}\text { 260,000 lbm } \\
\text { loco }\end{array}$ & $\begin{array}{l}40,000 \mathrm{lbm} \\
\text { truck }\end{array}$ & $\begin{array}{l}\text { 260,000 lbm } \\
\text { loco }\end{array}$ & $\begin{array}{l}40,000 \mathrm{lbm} \\
\text { truck }\end{array}$ \\
\hline Baseline & 4.5 & 11.5 & 7.4 & 18.7 \\
\hline $\begin{array}{l}\text { Extended side sill } \\
\text { only }\end{array}$ & 5.3 & 13.6 & 8.8 & 22.3 \\
\hline $\begin{array}{l}\text { Extended side sill, } \\
\text { stronger end beam }\end{array}$ & 6.1 & 15.4 & 10.2 & 26.1 \\
\hline
\end{tabular}

\section{Effectiveness of Strengthened Cab End Structures}

The second set of simulations examined the effectiveness of increasing the strength of several cab-end structural elements, including corner posts, collision posts, end beams and other lateral members connecting the corner and collision posts. This set of calculations was made to assess the response of baseline and modified cab ends in a collision representative of the Portage, Indiana accident in which a cab car collided into a steel coil resting on a flat bed truck. Two variations to scenario 2 were considered:

- A steel coil, offset about 60 inches from the axial centerline of the vehicle so that it is centered on a corner post, colliding with the cab car at a speed of $30 \mathrm{mph}$. The bottom of the coil is positioned flush with the floor of the cab car, so that the collision is centered vertically 36 inches above the floor.

- A variation to the above in which the coil is off-set only 23.5 inches from the axial centerline of the vehicle, and therefore centered about one of the collision posts. 
These two variations of collision scenario 2 are characterized by three primary structural features:

- The collision occurs well above the underframe (centered 36 inches above the floor), so that the collision generates a large moment about the underframe.

- The collision is offset-the coil strikes only one corner or collision post and generates a large moment about a vertical axis as well.

- The colliding object is relatively blunt (the coil is 72 inches in diameter)—one would not expect to observe fracture at the point of impact. (As noted earlier, in the Portage, Indiana accident, fracture was, in fact, observed several inches below the impact point, just above the top of shear reinforcement for the collision post. This fracture is likely due to the relatively high collision speed and the structural details in this location. This apparent inconsistency between model and observation serves as a reminder that fracture is a phenomenon that is very dependent upon local structural and material details and thus is hard to capture with a model of an entire vehicle end.)

The coil was modeled as a rigid cylinder with a mass of $103.5 \mathrm{lb}-\mathrm{sec}^{2} / \mathrm{in}$ (a weight of 40,000 lbm). An initial velocity of $30 \mathrm{mph}$ in the axial direction was prescribed to the rigid body, and it was not constrained against movement in the vertical and lateral directions. (It was not defined to have rotational degrees of freedom.) The cab car finite element mesh is shown with the rigid surface representation of a colliding steel coil in Figure 7. Contact was defined between the rigid surface and all of the nodes near the front of the cab car mesh.

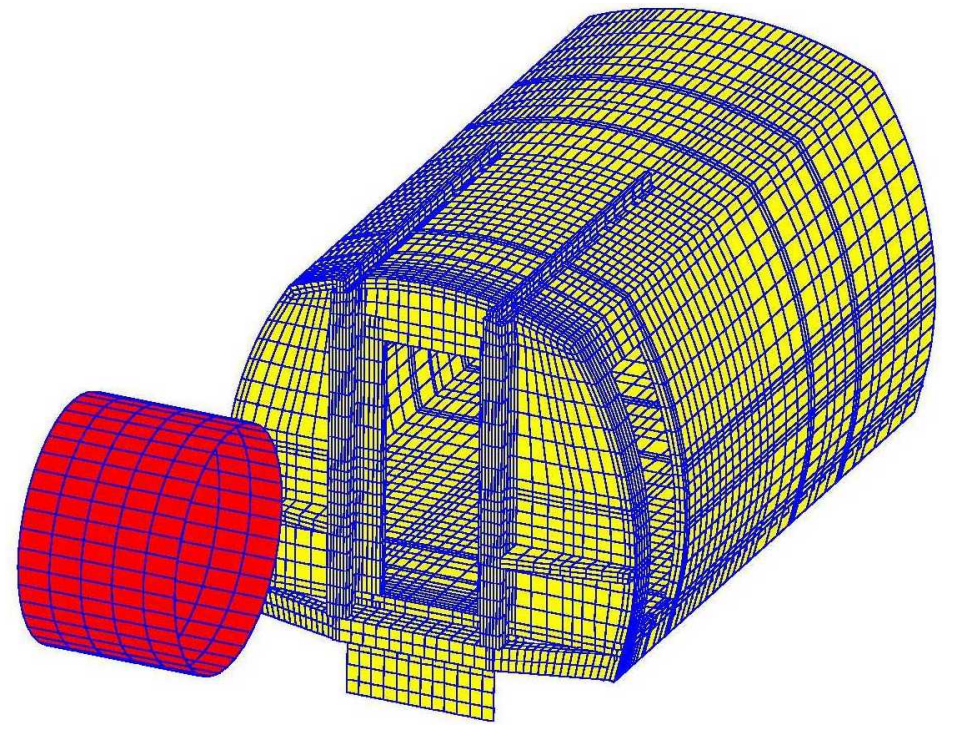

Figure 7. The finite element mesh used for the cab car crush calculations for collision with a rigid surface representing a colliding steel coil.

\section{Corner Post-Centered Crush}

The load-displacement response of the baseline cab end structure for the collision with the coil, centered about the corner post, is shown in Figure 7. The initial response shows a resistance level of about 100,000 lbf. This response is primarily due to crushing of the mid-height lateral support, which connects the collision post to the corner post on the modeled vehicle. Since the collision posts are positioned about 9 inches closer to the front of the cab car than the corner posts, this lateral support is loaded before the corner post. At a crush level of 9 inches, the coil impacts the corner post, and there is a narrow peak in load to 200,000 lbf associated with the dynamics of the impact. The load drops down to about 150,000 $\mathrm{lbf}$, and then proceeds to gradually increase to about 300,000 lbf at a crush level of about 32 inches. We note that, because the coil is 48 inches wide, it first loads the mid-height support at a point that is only 
about 15 inches away from the collision posts. The bending resistance of this support is much greater here than it is at it's connection to the corner post. Also, because the coil has a 72 inch diameter, it bends the collision post away from its connection with the end beam, so that the end beam does not deform nearly as much. At 32 inches of crush at the contact point, the end beam has only crushed about 15 inches.

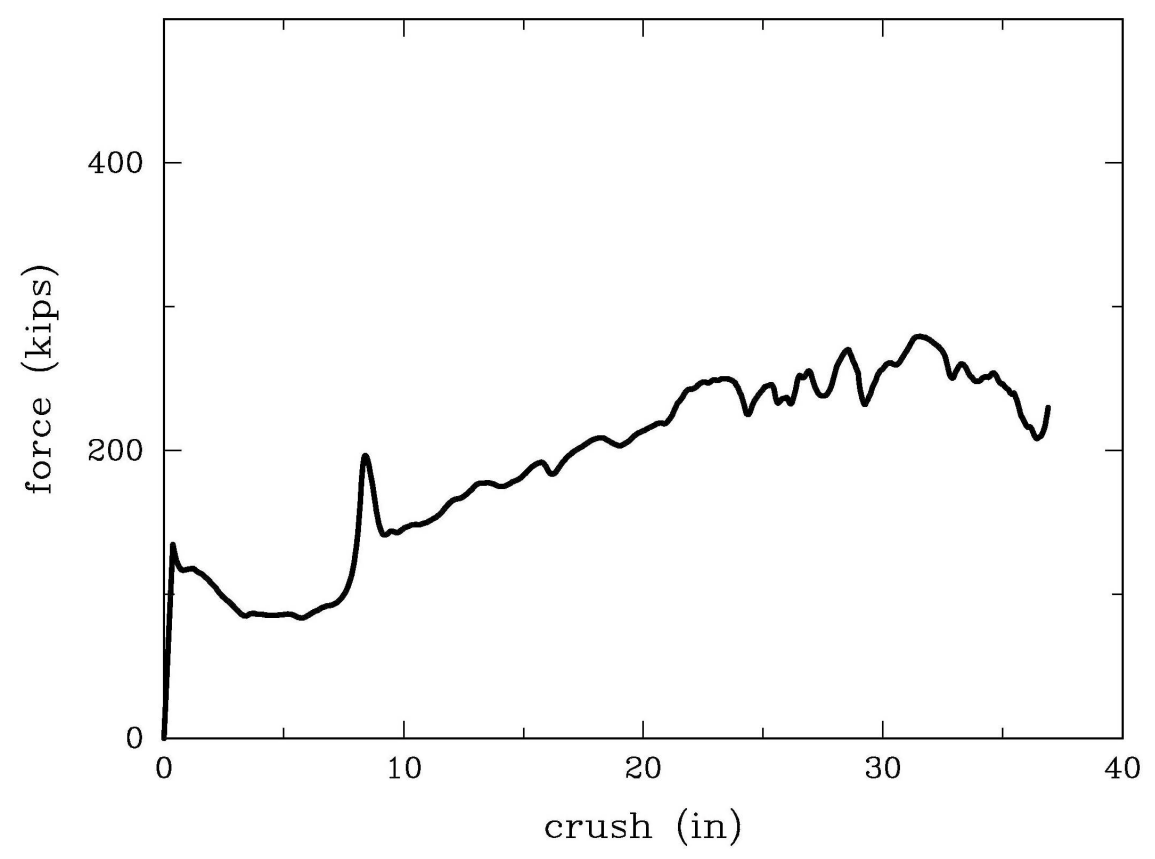

Figure 8. Predicted load-displacement response of the baseline cab end corner to corner post-centered collision with a steel coil.

Three different modifications to cab end structures were considered for this scenario:

- Case 1. The corner post and end beam were modified to withstand a 300,000 lbf load at the floor without exceeding the ultimate strength of the material and a 100,000 lbf load at 18 inches without exceeding yield (as compared to 150,000 lbf and 30,000 lbf, respectively, for the baseline case). In addition, the collision post was strengthened so that it was able to withstand a 400,000 lbf load anywhere from the floor to 30 inches.

- Case 2. In addition to the changes made for case 1, the top plate, which connects the top of the corner post to the top of the collision post, was strengthened considerably so that it could withstand a 150,000 lbf load without exceeding the ultimate strength of the steel.

- Case 3. In addition to the changes made for cases 1 and 2, the mid-height (26.5 inches off the floor) lateral support, connecting the collision post to the corner post, was strengthened so that it too could withstand a 150,000 load without exceeding the ultimate strength of the steel.

The load-displacement response of the modified cab end structure to a corner post-centered collision with the coil is shown in Figure 9 for each of the three cases. These curves indicate that strengthening the corner post and end beam (case 1) significantly increases the initial dynamic peak and the crush resistance in the interval from 10 to 20 inches. The curves shown in Figure 9 further show that increasing the strength of the top plate does not change the load-deformation response of the cab end for this particular scenario. It is likely, however, that a strengthened top plate would make a significant difference if an object collides near the top of the corner post. 


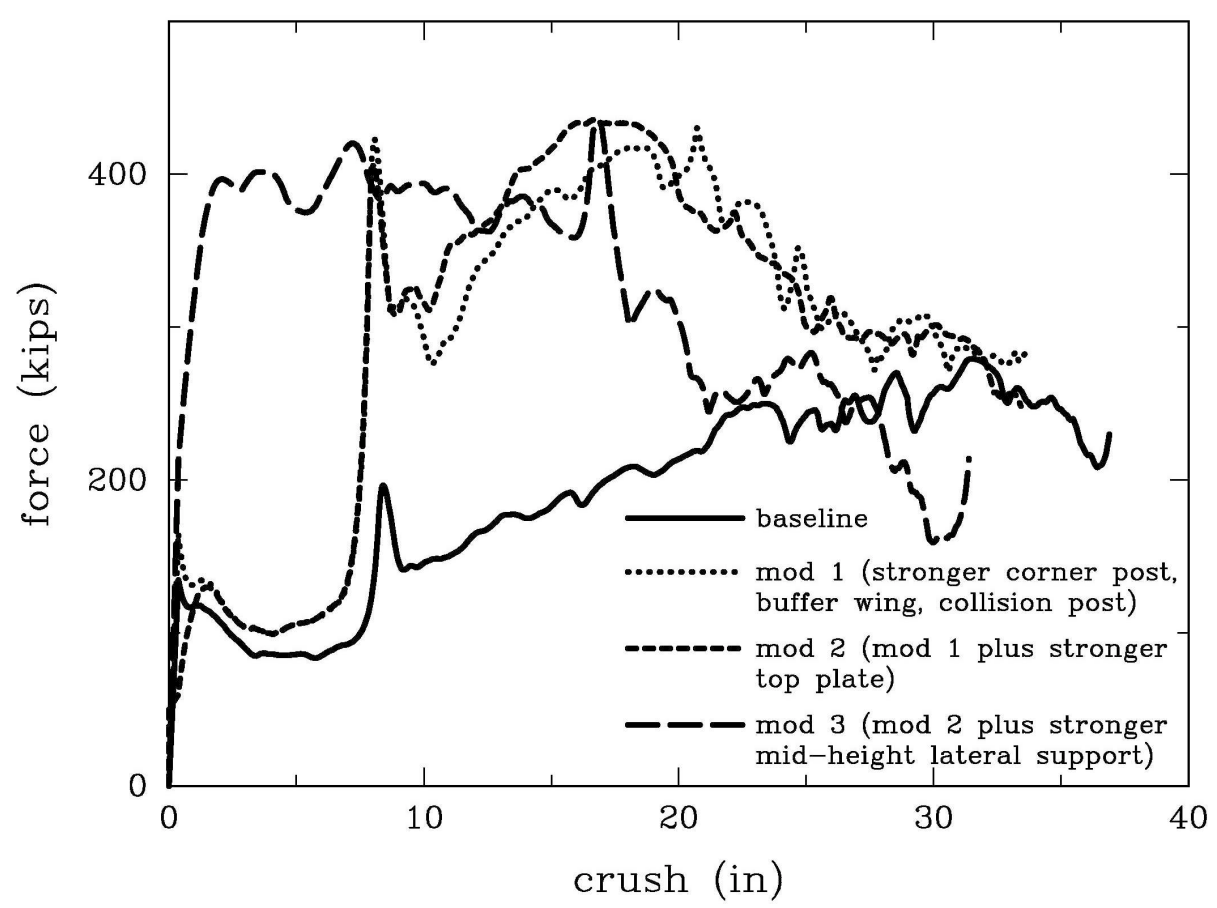

Figure 9. Comparison of predicted load-displacement response of baseline and three modified cab-endcorner structures for corner post-centered collision with a steel coil.

Finally, it appears that strengthening the mid-height lateral support makes a significant difference for this scenario. The response for this case indicates an immediate jump in load to 400,000 lbf that is sustained for two feet of crush before it begins to decrease. The immediate rise takes place because this lateral support is loaded immediately by the colliding rigid surface. The effectiveness of a mid-height lateral support for this scenario should not be surprising, since the point of contact (36 inches above the floor), is only 9.5 inches higher than the level of the support (26.5 inches).

Table 4 summarizes the results of the corner post-centered collision of the coil in terms of tolerable collision speed. The results shown in this table indicate that, in comparison to a collision with a locomotive, a collision with the steel coil can be tolerated at higher collision speeds.

Table 4. The effect of cab-end structural modifications on the speed at which the operator and passenger volumes become compromised in corner post-centered collisions with a coil.

\begin{tabular}{|l|c|c|}
\hline \multicolumn{1}{|c|}{ Case } & $\begin{array}{l}\text { Maximum safe closing speed for } \\
\text { the operator, in mph (based upon 1 } \\
\text { ft of crush) }\end{array}$ & $\begin{array}{l}\text { Maximum safe closing } \\
\text { speed for the passengers, } \\
\text { in mph (based upon 3 ft of } \\
\text { crush) }\end{array}$ \\
\hline Baseline & 13.0 & 21.8 \\
\hline $\begin{array}{l}\text { Modification 1: } \\
\text { strengthened corner } \\
\text { post, end beam and } \\
\text { collision post) }\end{array}$ & 17.4 & 24.1 \\
\hline $\begin{array}{l}\text { Mod. 2 (Mod. 1 plus } \\
\text { strengthened top } \\
\text { plate) }\end{array}$ & 17.0 & 24.2 \\
\hline $\begin{array}{l}\text { Mod. 3 (Mod. 1 plus } \\
\text { strengthened mid- } \\
\text { height lateral } \\
\text { support) }\end{array}$ & 19.0 & 28.2 \\
\hline
\end{tabular}


The results for the modified cases indicate that improvements to the maximum safe closing speed for the operator and passenger volumes increase by about $45 \%$ and $30 \%$, respectively.

\section{Collision-Post Centered Crush:}

The load-displacement response of the baseline and modified cab end structures to a collision with the coil, centered about a collision post, is shown in Figure 10. The response for the baseline case shows a narrow dynamic peak of about $320,000 \mathrm{lbf}$, which is followed by a period of reasonably steady crush load of about $200,000 \mathrm{lbf}$ to a crush of over 30 inches.

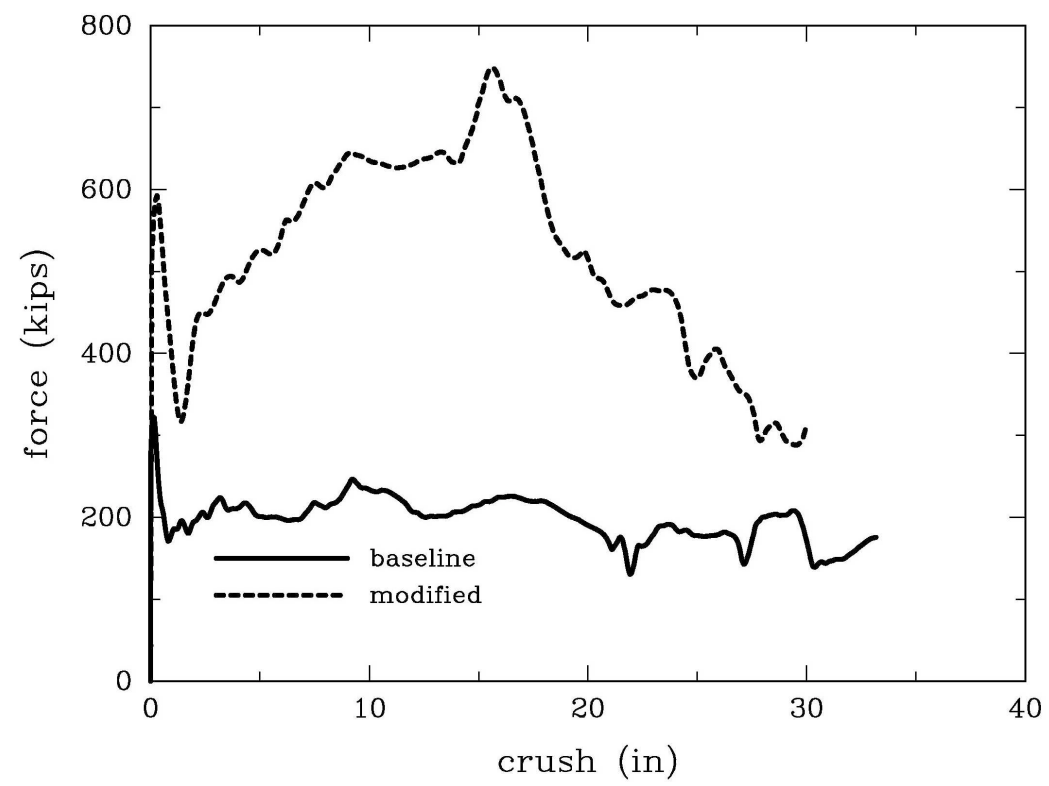

Figure 10. Comparison of load-displacement response to collision post-centered collision with a steel coil for a modified cab end $(300,000$ lbf collision post) to that of the baseline cab end.

The response of the modified cab end, with collision posts designed to resist 300,000 lbf up to 30 inches off the floor, indicates a tremendous increase in crush load. In this case the load builds gradually builds up to over 70,000 lbf at 15 inches of crush before dropping due to underframe buckling. Such behavior results in a significant degree of energy absorption over the first 30 inches of crush.

Table 5 summarizes the results of the collision post-centered collision of the coil in terms of tolerable collision speed for the baseline cab end and for the modified cab end with collision posts designed to resist 300,000 lbf. The results are similar to those shown in Table 4 and indicate that improvements to the maximum safe closing speed for the operator and passenger volumes increase by about $60 \%$ and $45 \%$, respectively.

Table 5. The effect of cab-end structural modifications on the speed at which the operator and passenger volumes become compromised in a corner post-centered collision with a coil.

\begin{tabular}{|l|c|c|}
\hline \multicolumn{1}{|c|}{ Case } & $\begin{array}{l}\text { Maximum safe closing speed for } \\
\text { the operator, in mph (based upon } \\
1 \mathrm{ft} \text { of crush) }\end{array}$ & $\begin{array}{l}\text { Maximum safe closing speed for } \\
\text { the passengers, in mph (based upon } \\
\text { 3 ft of crush) }\end{array}$ \\
\hline Baseline & 12.2 & 20.4 \\
\hline Modified & 19.2 & 29.7 \\
\hline
\end{tabular}




\section{SUMMARY AND DISCUSSION}

The results of the three sets of cab end crush simulations indicate that moderate to substantial increases in tolerable collision speeds can be achieved through straightforward modifications of front-end structures.

For the model cab car, extending the side sill forward to the corner alone provides an increase of 15 to 20 percent in tolerable collision speeds for the collision scenario representative of a locomotive underframe raking down the side of the vehicle. This relatively modest increase in safety is found because the mode of collapse of the side sill — buckling — is one that does not absorb much energy. It is likely that tolerable collision speeds can, in fact, be increased significantly through the design of a side sill that crushes in a controlled fashion rather than buckling.

The results for this scenario further show that strengthening the end beam clearly improves the energy capability of the corner structure for such collisions (by about 40 percent). Before implementing such changes in corner strength, however, one must consider the consequences of the larger impact forces that accompany these increases in strength.

For the corner post-centered collision with the coil, the model predicts increases in tolerated collision speeds ranging from $4 \mathrm{mph}$ (for $1 \mathrm{ft}$ of crush) to $7 \mathrm{mph}$ (for $3 \mathrm{ft}$ of crush). Likewise, for the collision postcentered collision with the coil, the model predicts increases in tolerated collision speeds of $7 \mathrm{mph}$ (for $1 \mathrm{ft}$ of crush) to $9 \mathrm{mph}$ (for $3 \mathrm{ft}$ of crush). These reasonably substantial increases in operator and passenger protection arise, in part, because of stronger lateral structural elements (particularly the end beam and the mid-height lateral support), which serve to carry more of the offset load to the much stronger collision posts. These transverse structural elements cause the cab end structure to behave more like a frame than a collection of beams, and therefore allow more of the cab-end structure to participate in absorbing the energy of the collision.

The limited improvement in safety predicted for scenario 1 for the case of an extended side sill only is an excellent illustration that specifications based upon strength alone are not sufficient to ensure safety in a collision. Further increases in tolerable collision speeds for cab cars can likely be achieved through detailed evaluations of crashworthiness as part of the design of key cab end structural elements. Design specifications posed only in terms of strength do not characterize the energy absorbing characteristics of structures. Buckling and fracture can limit energy absorption capability and should be considered in the design of end structures. Fracture does not appear to limit energy absorption for the modeled collisions; however, as was observed in the Portage Indiana accident, fracture can be a major factor determining energy absorption.

Moving forward, specifications for the design of crashworthy cab cars may be better posed in terms of energy absorption specified crush distances for a number of well-defined, representative collision scenarios.

\section{REFERENCES}

1. Mayville, R., Stringfellow, R., Rancatore, R., and Hosmer, T., "Locomotive Crashworthiness Research, Volume 5: Cab Car Crashworthiness Report, DOT/FRA/ORD-95/08.5, Federal Railroad Administration, U.S. Department of Transportation, 1996.

2. Tyrell, D., Severson, K., Mayville, R., Stringfellow, R., Berry, S., and Perlman, A., "Evaluation of Cab Car Crashworthiness Design Modifications," Institute of Electrical and Electronics Engineers, Cat. No. 97CH36047, pp. 49-58, March 1997

3. "Railroad Accident Report - Near Head-on Collision and Derailment of Two New Jersey Transit Commuter Trains Near Secaucus, New Jersey February 9, 1996," NTSB Report Number - RAR-9701, PB97-916301 (March 25, 1997).

4. "Collision and Derailment of Maryland Rail Commuter MARC Train 286 and National Railroad Passenger Corporation, AMTRAK Train 29 Near Silver Spring, MD on February 16, 1996"” NTSB Report Number - RAR-97-02, PB97-916302 . (June 17, 1997) Spring, MD accident. 
5. Railroad Accident Report - Head on Collision of Boston \& Main Corporation Extra 1731 East and Massachusetts Bay Transportation Authority Train No. 570, Beverly, Massachusetts, August 11, 1981. National Transportation Safety Board, Washington, D.C. 20594.

6. Railroad Accident Report - Collision between Northern Indiana Commuter Transportation District Eastbound Train 7 and Westbound Train 12 Near Gary, Indiana on January 18, 1993. National Transportation Safety Board, Washington, D.C. 20594.

7. Kirkpatrick, S., Simons, J., "High Speed Rail Collision Safety, Approach to Crashworthiness and Accident Survivability", Proceedings of the Symposium on Rail Vehicle Crashworthiness, June 1996, pp. IIA-3-1 to IIA-3-27, US Department of Transportation, DOT/FRA/ORD-97/08, March 1998.

\section{ACKNOWLEDGMENTS}

The authors gratefully acknowledge the support for this research provided by the Volpe Center of the Department of Transportation. In particular, we wish to thank David Tyrell for his technical guidance. We also wish to thank the many other individuals in the rail community who have been supportive of this work. 